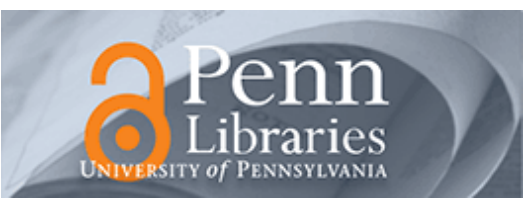

University of Pennsylvania ScholarlyCommons

July 2007

\title{
Relationship Between Dispersion Metric and Properties of PMMA/SWNT Nanocomposites
}

\author{
Takashi Kashiwagi \\ National Institute of Standards and Technology \\ Jeffrey Fagan \\ National Institute of Standards and Technology \\ Jack F. Douglas \\ National Institute of Standards and Technology \\ Kazuya Yamamoto \\ National Institute of Standards and Technology \\ Alan N. Heckert \\ National Institute of Standards and Technology
}

See next page for additional authors

Follow this and additional works at: https://repository.upenn.edu/mse_papers

\section{Recommended Citation}

Kashiwagi, T., Fagan, J., Douglas, J. F., Yamamoto, K., Heckert, A. N., Leigh, S. D., Obrzut, J., Du, F., LinGibson, S., Mu, M., Winey, K. I., \& Haggenmueller, R. (2007). Relationship Between Dispersion Metric and Properties of PMMA/SWNT Nanocomposites. Retrieved from https://repository.upenn.edu/mse_papers/ 136

Postprint version. Published in Polymer, Volume 48, Issue 16: July 2007, pages 4855-4866.

Publisher URL: http://dx.doi.org/10.1016/j.polymer.2007.06.015

This paper is posted at ScholarlyCommons. https://repository.upenn.edu/mse_papers/136

For more information, please contact repository@pobox.upenn.edu. 


\title{
Relationship Between Dispersion Metric and Properties of PMMA/SWNT Nanocomposites
}

\author{
Abstract \\ Particle spatial dispersion is a crucial characteristic of polymer composite materials and this property is \\ recognized as especially important in nanocomposite materials due to the general tendency of \\ nanoparticles to aggregate under processing conditions. We introduce dispersion metrics along with a \\ specified dispersion scale over which material homogeneity is measured and consider how the dispersion \\ metrics correlate quantitatively with the variation of basic nanocomposite properties. We then address \\ the general problem of quantifying nanoparticle spatial dispersion in model nanocomposites of single \\ wall carbon nanotubes (SWNT) dispersed in poly(methyl methacrylate) (PMMA) at a fixed SWNT \\ concentration of $0.5 \%$ using a 'coagulation' fabrication method. Two methods are utilized to measure \\ dispersion, UV-Vis spectroscopy and optical confocal microscopy. Quantitative spatial dispersion levels \\ were obtained through image analysis to obtain a 'relative dispersion index' (RDI) representing the \\ uniformity of the dispersion of SWNTs in the samples and through absorbance. We find that the storage \\ modulus, electrical conductivity, and flammability containing the same amount of SWNTs, the \\ relationships between the quantified dispersion levels and physical properties show about four orders of \\ magnitude variation in storage modulus, almost eight orders of magnitude variation in electric \\ conductivity, and about $70 \%$ reduction in peak mass loss rate at the highest dispersion level used in this \\ study. The observation of such a profound effect of SWNT dispersion indicates the need for objective \\ dispersion metrics for correlating and understanding how the properties of nanocomposites are \\ determined by the concentration, shape and size of the nanotubes.
}

\section{Keywords}

particle dispersion metric, relative dispersion index, nanocomposite, carbon nanotubes

\section{Comments}

Postprint version. Published in Polymer, Volume 48, Issue 16: July 2007, pages 4855-4866.

Publisher URL: http://dx.doi.org/10.1016/j.polymer.2007.06.015

\section{Author(s)}

Takashi Kashiwagi, Jeffrey Fagan, Jack F. Douglas, Kazuya Yamamoto, Alan N. Heckert, Stefan D. Leigh, Jan Obrzut, Fangming Du, Sheng Lin-Gibson, Minfang Mu, Karen I. Winey, and Reto Haggenmueller 


\title{
Relationship Between Dispersion Metric and Properties of PMMA/SWNT Nanocomposites ${ }^{\dagger}$
}

\author{
Takashi Kashiwagi ${ }^{1+}$, Jeffrey Fagan ${ }^{2}$, Jack F. Douglas ${ }^{2}$, Kazuya Yamamoto ${ }^{1}$, \\ Alan N. Heckert ${ }^{3}$, Stefan D. Leigh ${ }^{3}$, Jan Obrzut ${ }^{2}$, Fangming Du ${ }^{4}$, Sheng Lin-Gibson ${ }^{2}$, \\ Minfang $\mathrm{Mu}^{4}$, Karen I. Winey ${ }^{4}$, Reto Haggenmueller ${ }^{1}$ \\ ${ }^{1}$ Fire Research Division, National Institute of Standards and Technology, Gaithersburg, \\ MD 20899, USA \\ ${ }^{2}$ Polymers Division, National Institute of Standards and Technology, Gaithersburg, MD \\ 20899, USA \\ ${ }^{3}$ Statistical Engineering Division, National Institute of Standards and technology, \\ Gaithersburg, MD 20899, USA \\ ${ }^{4}$ Department of Chemical and Biomolecular Engineering, University of Pennsylvania, \\ Philadelphia, PA 19104, USA
}

Key Words: particle dispersion metric, relative dispersion index, nanocomposite, carbon nanotubes

Abstract: Particle spatial dispersion is a crucial characteristic of polymer composite materials and this property is recognized as especially important in nanocomposite materials due to the general tendency of nanoparticles to aggregate under processing conditions. We introduce dispersion metrics along with a specified dispersion scale over which material homogeneity is measured and consider how the dispersion metrics correlate quantitatively with the variation of basic nanocomposite properties. We then address the general problem of quantifying nanoparticle spatial dispersion in model nanocomposites of single wall carbon nanotubes (SWNT) dispersed in poly(methyl methacrylate) (PMMA) at a fixed SWNT concentration of $0.5 \%$ using a 'coagulation' fabrication method. Two methods are utilized to measure dispersion, UV-Vis spectroscopy and optical confocal microscopy. Quantitative spatial dispersion levels were obtained through image analysis to obtain a 'relative dispersion index' (RDI) representing the uniformity of the dispersion of SWNTs in the samples and through absorbance. We find that the storage modulus, electrical conductivity, and flammability

\footnotetext{
${ }^{\dagger}$ This was carried out by the National Institute of Standards and Technology (NIST), an agency of the US Government and is not subject to copyright in the US.

$¥$ Correspondence to: T. Kashiwagi (E-mail: takashi.kashiwagi@nist.gov)
} 
property of the nanocomposites correlates well with the RDI. For the nanocomposites containing the same amount of SWNTs, the relationships between the quantified dispersion levels and physical properties show about four orders of magnitude variation in storage modulus, almost eight orders of magnitude variation in electric conductivity, and about $70 \%$ reduction in peak mass loss rate at the highest dispersion level used in this study. The observation of such a profound effect of SWNT dispersion indicates the need for objective dispersion metrics for correlating and understanding how the properties of nanocomposites are determined by the concentration, shape and size of the nanotubes.

\section{Introduction}

Since the discovery of carbon nanotubes (CNTs) by Iijima [1], extensive studies have been conducted exploring their unique electronic, thermal, optical, and mechanical properties and their potential use in greatly enhancing the physical properties of polymer nanocomposites $[2,3,4,5,6]$, as summarized in recent review articles $[7,8]$. The outstanding properties are in part attributed to their extremely high aspect ratio (lengthto-outer diameter ratio) of up to 1000 . It is often stated that the full realization of the reinforcement potential of CNTs requires good spatial dispersion of the CNTs in the polymer and efficient interfacial stress transfer between the CNTs and the polymer matrix [7]. To address this general problem, we must first define some objective method defining what 'good dispersion' means. In particular, we need some kind of dispersion metric to evaluate the role of dispersion on nanocomposite properties.

In attempts to achieve well-dispersed CNTs in a polymer, functionalization of the CNT walls $[9,10]$, use of surfactants [11], controlled duration of sonication of mixtures of CNTs in various solvents $[12,13,14,15,16]$, in situ polymerization under sonication [17], in situ bulk polymerization [18], high speed mechanical stirring [19,20], and compounding using a twin screw extruder $[21,22]$ have been used. The dispersion of the CNTs in the polymer was mainly determined by taking images using transmission electron microscopy (TEM), scanning electron microscopy (SEM), or optical microscopy. Most studies provide only a qualitative measure of dispersion of the CNTs, without a specification of the length scale over which these characterization are made 
along with the scale over which this metrics applied. A quantitative measure of spatial dispersion of nanoparticles is critically needed to understand the relationship between the original sample characterization and the physical properties of nanocomposites [23]. Further improvement in the physical properties of nanocomposite could be achieved from such a relationship [24].

To develop such a quantitative relationship, papers describing quantitative characterizations of the dispersion of nanoparticles have been recently published. Four different methods using small-angle neutron scattering, near-infrared fluorescence measurement, optical absorption spectroscopy, and resonant Raman scattering were applied to determine the dispersion of DNA-wrapped single-walled carbon nanotubes (SWNT) in poly(acrylic acid) [25]. The morphology of dispersed SWNT was determined by light scattering [12] and the length and the diameter of multi-walled carbon nanotubes (MWNT) suspended in an aqueous solution were determined by analysis of the images taken by field emission gun scanning microscope [15]. The dispersion level of SWNTs in poly(methyl methacrylate) (PMMA) was characterized by producing a Raman map over a $40 \mu \mathrm{m}$ by $40 \mu \mathrm{m}$ domain by measuring Raman scattering intensity [13]. A value of the mean standard deviation (SD) of the Raman scattering intensity over the map was used as a quantitative dispersion index of the SWNTs in the PMMA. (A small value of standard deviation in the intensity represents good dispersion.) A similar approach measuring intensity variation of a fluorescence signal from Nile blue dye distributed in polystyrene of PS/MWNT nanocomposites using a laser scanning confocal microscope was reported for determining the quantitative level of dispersion over a large domain size of about 150 $\mu \mathrm{m}$ square [26]. An extensive image analysis of TEM images of PMMA-montmorillonite and PMMA-Bentonite nanocomposites was conducted to determine quantitative quantities of exfoliation of the clay particles [27]. The dispersion of SWNT in surfactants was determined by optical absorption spectroscopy but the relation with physical properties was not obtained [28]. Other detailed, statistical analyses of the dispersion of montmorillonites in polyvinylchloride [29] and of carbon blacks (CB) in polyamide 6 [30] over a $5 \mu \mathrm{m}$ by $5 \mu \mathrm{m}$ domain were conducted by the quantitative image analysis of the SEM images utilizing the quadrat method of Morishita [31]. The dispersion pattern of 
$\mathrm{CBs}$, including small and large aggregates, was estimated by the analysis and Morishita's index was introduced as a quantitative measure of the dispersion of CBs.

Although many quantitative physical properties of CNT nanocomposites have been previously subject to experimental investigation, the dispersion characteristic of nanocomposites has not been measured, except in the few cases discussed above where some limited quantification is considered. The objective of this study is to determine the quantitative relationship between quantitative dispersion levels and the physical properties of CTN nanocomposites. And, more generally, to establish a sound philosophical approach to this problem when the spatial scales of dispersion are prescribed in the measurements of dispersion determined. In this study, multiple dispersion levels of PMMA/SWNT nanocomposites are prepared using the coagulation method, which is chosen since it can lead to highly variable status of particle dispersion. The level of dispersion of SWNTs in PMMA for each nanocomposite is quantitatively determined by two different methodologies. Physical properties such as viscoelastic properties, electrical conductivity, mechanical properties, and flammability properties are then measured for each nanocomposite and the relationships among the physical properties and the measures of dispersion determined. This approach allows for a more rational comparison of the reinforcement performance of polymer by different types of nanoparticles with the measured dispersion indices of the nanoparticles.

\section{Experimental Section}

Sample Preparation. The matrix polymer used in this paper is poly(methyl methacrylate) (PMMA) (Polysciences* ${ }^{*} \mathrm{M}_{\mathrm{w}}$ : 100,000 $\mathrm{g} / \mathrm{mol}$ ). SWNTs for the nanocomposites, synthesized by the high-pressure carbon monoxide method (HiPCo) [32], were provided by Carbon Nanotechnologies inc. and Foster Miller Co.. The metal residue in the SWNTs is less than 13 mass \%. The coagulation method was used to produce the SWNT/PMMA nanocomposites [33]. In the coagulation method, dimethylformamide (DMF) was chosen to dissolve the PMMA and to permit dispersion

\footnotetext{
* Certain commercial equipment, instruments, materials, services or companies are identified in this paper in order to specify adequately the experimental procedure. This in no way implies endorsement or recommendation by NIST.
} 
of the SWNTs by bath sonication for $24 \mathrm{~h}$. To obtain good nanotube dispersion, the nanotube concentration in DMF is critical. We can observe nanotube agglomerates by the naked eye at a concentration higher than $0.4 \mathrm{mg} / \mathrm{ml}$, while the $0.2 \mathrm{mg} / \mathrm{ml}$ suspension is visually homogeneous. Therefore, we can control the nanotube dispersion in the nanocomposites by changing the nanotube concentration in DMF, assuming that the state of nanotube dispersion is comparable in DMF before coagulation and in the polymer matrix after coagulation suspension [13]. Concentrations of $0.05 \mathrm{mg} / \mathrm{ml}, 0.1 \mathrm{mg} / \mathrm{ml}, 0.2$ $\mathrm{mg} / \mathrm{ml}, 0.4 \mathrm{mg} / \mathrm{ml}, 0.8 \mathrm{mg} / \mathrm{ml}$, and $1.2 \mathrm{mg} / \mathrm{ml}$ were used to make nanocomposites with various levels of dispersion. The concentration of SWNTs in PMMA was 0.5 mass \% for all samples. All samples for the physical measurement were compression molded at 200 ${ }^{\circ} \mathrm{C}$ under pressure of about 1.4 Mpa for a duration of $15 \mathrm{~min}$.

Development of an Objective Dispersion Metric. Two different methodologies were used to characterize the quantitative dispersion level of SWNTs in PMMA. One was to take images of a thin film of each PMMA/SWNT sample using confocal microscopy which allows a large observation domain size of about $100 \mu \mathrm{m}$ compared to much smaller domain size of about $1 \mu \mathrm{m}$ by TEM or SEM. The other method was absorption measurement on a thin film of the sample using UV-visible and near infrared spectroscopy. Its observation size of about $3 \mathrm{~mm}$ x $10 \mathrm{~mm}$ x $200 \mu \mathrm{m}$ thickness was much larger than that achieved by confocal microscopy. All films were made by compression molding. A small amount of sample was placed between thin Kapton films which covered two mechanically buffed brass plates. A $200 \mu \mathrm{m}$ thick shim plate (with a round hole in the center) was inserted between the two plates to produce a uniform film.

(a) A laser scanning confocal microscope (Model LSM510, Carl Zeiss Inc.) was used to image the SWNTs in the PMMA matrix. The confocal microscope utilizes coherent laser light and collects reflected light exclusively from a single plane with a thickness of about $100 \mathrm{~nm}$ (a pinhole sits conjugated to the focal plane and rejects light out of the focal plane). However, the smooth front surface was required to define the surface location. A red laser $(\lambda=633 \mathrm{~nm})$ was used as the coherent light and images were taken at 100x magnification with an Epiplan-Neofluar 100 x/1.30 oil-pool objective. An LP385 (Rapp OptoElectronic) filter was used to limit the lower spectra of reflected light. 
One hundred two-dimensional images (optical slices with 1024 pixels x 1024 pixels), with scan size $92.1 \times 92.1 \mu \mathrm{m}$, were taken at a spacing of $100 \mathrm{~nm}$ by moving the focal plane.

Several different spatial statistical analyses were conducted with our sample of one hundred images. As a first assay of distance from uniformity, the standard $\chi^{2}$ statistic $^{34}$

$$
\chi^{2}=\Sigma_{\text {cells }} \frac{[\text { Observed }- \text { Uniform }]^{2}}{\text { Uniform }}
$$

was computed for each sample across a range of cubic cell sizes, ranging from the size of $0.46 \mu \mathrm{m} \times 0.46 \mu \mathrm{m} \times 0.50 \mu \mathrm{m}$ to about $9.2 \mu \mathrm{m} \times 9.6 \mu \mathrm{m} \times 10 \mu \mathrm{m}$. The cubic cell gridding scheme was consistently applied, for all samples, to the observation domain consisting of 100 slices of a $1024 \times 1024$ pixel image. Initial computations were done in the gray scale presented by the data. Ultimately, however, comparison to an estimated background and recoding of pixels as "nanotube present" or "nanotube not present" ( 1 or 0$)$ was employed to the computation of this and other statistics. In each case, for each density and cube size, the expected "Uniform" density cell content was computed as the total number of pixels with nanotube present divided by the total number of cubes scanned. Portions of the solid rectangle of data being binned and scanned that did not fall within the binning scheme, boundary areas, were excluded from the counting.

Another, more direct, approach to quantifying the degree of nonconformance of the distribution of carbon nanotubes in the PMMA matrix to a uniform distribution is to compute a distance between the empirical and ideal (uniform) distributions. The ideal is derived directly from the masses of materials used in the preparation of the composite. The empirical is computed by tallying nanotubes present in a volume partition of composite material. The variational distance is commonly employed in mathematical statistics, for example in determining rates of convergence of one distribution to another. Among multiple equivalent definitions

$$
\mathrm{d}=\frac{1}{2} \sum_{k=0}^{k=\infty}|P(\mathrm{UNIF}=k)-P(\mathrm{EMPIR}=k)|
$$


is the simplest to apply [35]. Domain by domain, one evaluates the difference between the uniform-predicted probability of occurrence of a nanotube and the observed probability. One sums the absolute values of all such differences and divides by two. The functional described by the formula is a true distance, symmetric in its two arguments, and satisfying the triangle inequality. The factor $\frac{1}{2}$ ensures that the distance takes values between 0 and 1 .

We prefer to work here in terms of a linearly transformed variational distance, which we term 'Relative Dispersion Index',

$$
\mathrm{RDI}=100 \cdot(1-\mathrm{d})
$$

Relative dispersion of 100 connotes perfect conformance to uniform, with successively lower values, down to zero, indicating less and less conformity.

$\mathrm{UV}$, visible and near infrared absorption measurements were performed on PMMA-SWNT composites over the wavelength range of $190 \mathrm{~nm}$ to $2750 \mathrm{~nm}$, using a PerkinElmer Lambda 950 UV-Vis-NIR spectrophotometer in transmission mode. The recorded spectra were corrected for the instrument background and dark current, as well as for absorbance of the PMMA polymer. The polymer signal was subtracted using the Beer-Lambert law ${ }^{\S}$,

$$
A=\varepsilon(C, \text { dispersion }) * C * L
$$

in which $A=\ln \left(I_{0} / I\right)$ is the absorbance, $\mathrm{C}$ the concentration, $\mathrm{L}$ the path length, and $\varepsilon$ is a parameter that depends on the concentration and dispersion of the SWNTs. Subtraction was performed by matching the absorbance of a pure PMMA blank and the PMMA components of the PMMA-SWNT composites over the $2700 \mathrm{~nm}$ to $1800 \mathrm{~nm}$ wavelength range. In particular, the magnitude of the PMMA blank subtraction was set by the elimination of a spectral feature at $2245 \mathrm{~nm}$ due solely to the polymer matrix. (Since absorbance has a linear relation to the film thickness, the difference in thickness between PMMA and PMMA/SWNTs is corrected by subtracting the spectral feature at $2245 \mathrm{~nm}$.

$\S$ Homogeneity of the sample is assumed in the Beer-Lambert law. In this instance however, the composites are inhomogeneous, any extinction coefficient calculated should not be viewed as intrinsic to the SWNTs, but rather as a function of the processing variables that led to the observed dispersion of the SWNTs within the polymer. 
No actual thickness measurement was conducted. We estimate accuracy of $\pm 2 \%$ for this procedure.) For PMMA in this situation $\varepsilon$ and $\mathrm{C}$ are constants.

Property Measurements. Thermal gravimetric analyses (TGA) were conducted using a TA Instruments TGA Q 500 and a platinum pan at $5{ }^{\circ} \mathrm{C} / \mathrm{min}$ from 90 ${ }^{\circ} \mathrm{C}$ to $500{ }^{\circ} \mathrm{C}$ in nitrogen (flow rate of $60 \mathrm{~cm}^{3} / \mathrm{min}$ ). The standard uncertainty of the sample mass measurement is $\pm 1 \%$.

Viscoelastic measurements were performed on a Rheometric solid analyzer (RSAII) in oscillatory shear with a sandwich fixture. Frequency sweep with the sample size of $12.5 \mathrm{~mm} \times 16 \mathrm{~mm} \times 0.5 \mathrm{~mm}$ was performed at $200{ }^{\circ} \mathrm{C}$ with a strain of $0.5 \%$. Results were reproducible after one frequency sweep, indicating that there was no degradation of the sample or additional nanotube alignment during the measurement.

Electrical conductivities of the nanocomposites were measured at room temperature. A thin film, typically about $100 \mu \mathrm{m}$ thickness, was made by compression molding at $200{ }^{\circ} \mathrm{C}$ under the pressure of $1.4 \mathrm{MPa}$ for the duration of $15 \mathrm{~min}$. Gold electrodes with a thickness of $0.1 \mu \mathrm{m}$ were prepared by sputtering in Argon. We used a parallel plate electrode configuration where the diameter of the top electrode was 10.0 $\mathrm{mm}$ while the diameter of the bottom electrode was about $13 \mathrm{~mm}$. The conductivity was obtained from the complex impedance measurements (impedance magnitude $Z^{*}$ and the corresponding phase angle, $\theta$ ), which were carried out in a frequency range of $40 \mathrm{~Hz}$ to $50 \mathrm{MHz}$ through a four-terminal technique using an Agilent 4294A Precision Impedance Analyzer. The output $A C$ voltage was $0.5 \mathrm{~V}$. The complex electrical conductivity $\sigma^{*}$ was obtained from the measured complex impedance $Z^{*}$ normalized by the geometry of the test sample $\sigma^{*}=t /\left(Z^{*} a\right)$, where $t$ is the specimen thickness and $a$ is the area of the top electrode The combined relative experimental uncertainty of the measured complex conductivity magnitude was within $8 \%$, while the relative experimental uncertainty of the dielectric phase angle measurements was about $1 \%$.

A radiant gasification apparatus, similar to a cone calorimeter, was designed and constructed at NIST to study the gasification processes of samples by measuring mass loss rate and temperatures of the sample exposed to a fire-like heat flux in a nitrogen atmosphere (no burning). A disc shape sample was mounted horizontally and its top 
surface was exposed to a well-characterized thermal radiant flux from an electrical heating element. The weight of the sample was continuously measured by a sensitive weight device and mass loss rate was calculated by taking the time derivative of the weight. The observed mass loss rate in this device correlates well with heat release rate (a direct measure of the size of a fire) of polymer-CNT nanocomposites [22,36] and polymer-clay nanocomposites [37]. The apparatus consists of a stainless-steel cylindrical chamber that is $1.70 \mathrm{~m}$ tall and $0.61 \mathrm{~m}$ in diameter. In order to maintain a negligible background heat flux, the interior walls of the chamber are painted black and the chamber walls are water-cooled to $25^{\circ} \mathrm{C}$. All experiments were conducted at an incident radiant flux of $50 \mathrm{~kW} / \mathrm{m}^{2}$. The unique nature of this device is twofold: (1) observation and results obtained from it are based solely on the condensed phase processes due to the absence of any gas phase oxidation reactions and processes; (2) it enables visual observation of gasification behavior of a sample using a video camera under a radiant flux similar to that of a fire without any interference from a flame. A more detailed discussion of the apparatus is given in our previous study [38]. The standard uncertainty of the measured mass loss rate is $\pm 10 \%$.

\section{Results}

\section{Application of Dispersion Metric to Model PMMA/SWNT Nanocomposites}

Three-dimensionally reconstructions of the confocal microscopy images of each sample with the concentration of SWNT in DMF at $0.2 \mathrm{mg} / \mathrm{ml}, 0.4 \mathrm{mg} / \mathrm{ml}, 0.8 \mathrm{mg} / \mathrm{ml}$, and $1.2 \mathrm{mg} / \mathrm{ml}$ are shown in Figure 1. These images show SWNT bundles and agglomerates. Transparent areas correspond to PMMA. The image of $1.2 \mathrm{mg} / \mathrm{ml}$ shows numerous, large agglomerates, but such agglomerates are hardly seen in the images of 0.2 $\mathrm{mg} / \mathrm{ml}$ and $0.4 \mathrm{mg} / \mathrm{ml}$.

Quantitative spatial uniformity of SWNT in PMMA was determined by calculating the variational distance described in the previous section. Domain by domain, one evaluates the difference between the uniform-predicted probability of occurrence of a nanotube and the observed probability. The ideal uniform distance of SWNT bundle was calculated from an estimated total number of SWNT bundles in the observation area of the confocal microscopy. The average size of SWNT bundles was about $7 \mathrm{~nm}$ in diameter 
and $310 \mathrm{~nm}$ in length [13] and it was assumed that the bundle size was same for all samples. With $0.5 \mathrm{wt} \%$ of SWNT in the observation area of $92 \mu \mathrm{m} \times 92 \mu \mathrm{m} \times 10 \mu \mathrm{m}$, there were about $2 \times 10^{7}$ SWNT bundles. The variational distance was calculated by Equation (2) and subsequently relative dispersion index, RDI, representing the quantitative uniformity of the dispersion of SWNT bundles within the nanocomposite was calculated by Equation (3). RDI varies from $100 \%$ for a perfect uniform distribution to a poorest value of $0 \%$. The RDI values of the six samples are shown in Figure 2 as a function of the domain size. Here, one domain size (92 $\mu \mathrm{m}$ divided by 1092 and $10 \mu \mathrm{m}$ divided by 100) is about $90 \mathrm{~nm} \times 90 \mathrm{~nm} \times 100 \mathrm{~nm}$. All RDI values increase gradually with the domain size. The highest RDI is about $85 \%$ for $0.4 \mathrm{mg} / \mathrm{ml}$ and the lowest is about $15 \%$ for $1.2 \mathrm{mg} / \mathrm{ml}$.

The corresponding values of $\chi^{2}$ were calculated for the six samples as an additional indication of quantitative uniformity of the dispersion of SWNT bundles within the nanocomposite. The results are shown in Figure 3. A lower a value of $\chi^{2}$ indicates better uniformity. The trend of the three different levels of the uniformity, best with $0.2 \mathrm{mg} / \mathrm{ml}$ and $0.4 \mathrm{mg} / \mathrm{ml}$, middle group of $0.05 \mathrm{mg} / \mathrm{ml}, 0.1 \mathrm{mg} / \mathrm{ml}$, and $0.8 \mathrm{mg} / \mathrm{ml}$, and the poorest with $1.2 \mathrm{mg} / \mathrm{ml}$, is similar to the pattern with RDI shown in Figure 2 . However, the $0.2 \mathrm{mg} / \mathrm{ml}$ sample displays the best uniformity by the $\chi^{2}$ analysis compared to $0.4 \mathrm{mg} / \mathrm{ml}$ for the RDI analysis.

The absorption spectra of the polymer-SWNT composites vary systematically with the initial loading concentration of the SWNTs in DMF, as shown in Figure 4. Each absorption spectrum was scaled by the known path length through the sample to a constant thickness equal to that of the PMMA blank. Composite films cast from the most dilute suspensions $(0.1 \mathrm{mg} / \mathrm{ml}$ and $0.2 \mathrm{mg} / \mathrm{ml})$ show higher total absorption and sharper definition of the SWNT van-Hove transitions than the films cast from higher concentrated suspensions $(0.8 \mathrm{mg} / \mathrm{ml}, 1.2 \mathrm{mg} / \mathrm{ml})$. In a poorly dispersed film containing large aggregates, a large fraction of the total nanotube mass is contained within a small volume of the composite. This leaves regions of low nanotube content, in which a large fraction of the photons are transmitted. Due to the logarithmic relation between the total transmitted light over the transmission area and the measured absorption given by Eq. (5), a few regions of high transmittance will dominate the observed absorbance. 


$$
A=-L O G_{10}\left(\int_{\text {area }} T d(\text { area })\right)
$$

This effect is illustrated schematically in Figure 5 (a). Due to the logarithmic scaling, nanotubes within aggregates tend not to contribute as significantly to the measured spectrum. A larger absorbance for a constant film thickness and nanotube concentration is thus indicative of a better uniformity of SWNT dispersion within the nanocomposite. The composite films used for the UV-Vis-NIR measurements are shown in Figure 5 (b). The trend in opacity of the samples seen in this figure is apparent in the photograph. Although some variation in the films is apparent, this is primarily due to variations in the local thickness of the films. Multiple spectra were recorded for each film and most of the variation was removed by normalization to the thickness of the PMMA blank. The data shown in Figure 4 are the averages of the scaled spectra for the individual samples.

As shown in Figs. 2 and 3, the values of RDI and of $\chi^{2}$ are not constant and depend on multiple parameter choices. Therefore, the values of these parameters must be specified as RDI (spatial resolution, statistical analysis domain size, observation image size, and a number of observations at selected locations in a sample) to carefully characterize under what conditions these values are obtained. In this study, spatial resolution is $0.1 \mu \mathrm{m}$, statistical analysis domain size is selected at $1 \mu \mathrm{m}^{3}$ corresponding to the domain (cell) size of 12 in the two figures, observation image size is $92 \mu \mathrm{m} \times 92 \mu \mathrm{m} \times$ $10 \mu \mathrm{m}$, and the number of observations in a physical measurement sample is 1 (only one location).

The calculated values of scaled absorbance at $275 \mathrm{~nm}$, RDI $\left(0.1 \mu \mathrm{m}, 1 \mu \mathrm{m}^{3}\right.$, $\left.84,640 \mu \mathrm{m}^{3}, 1\right)$, and $\chi^{2}\left(0.1 \mu \mathrm{m}, 1 \mu \mathrm{m}^{3}, 84,640 \mu \mathrm{m}^{3}, 1\right)$ with respect to SWNT concentrations in DMF are listed in Table 1. It was anticipated that a lower concentration of SWNT in DMF would lead to an improved dispersion of SWNTs in the polymer. However, it appears that the dispersion does not get better beyond about the concentration of $0.2 \mathrm{mg} / \mathrm{ml}$ in DMF. This might be due to poor interaction of the tubes with polymer chains in a large volume of DMF at a low concentration.

The relationship among the RDI $\left(0.1 \mu \mathrm{m}, 1 \mu \mathrm{m}^{3}, 84,640 \mu \mathrm{m}^{3}, 1\right), \chi^{2}(0.1 \mu \mathrm{m}, 1$ $\left.\mu \mathrm{m}^{3}, 84,640 \mu \mathrm{m}^{3}, 1\right)$ value, and the absorbance is shown in Figure 6 . The absorbance is selected at $275 \mathrm{~nm}$, whose value is near the largest as shown in Figure 5. The trend 
shown in Figure 6 is not significantly modified by selecting a different domain size for determining RDI and $\chi^{2}$ value and absorbance at a different wavelength such as $426 \mathrm{~nm}$. The correlation coefficient between RDI $\left(0.1 \mu \mathrm{m}, 1 \mu \mathrm{m}^{3}, 84,640 \mu \mathrm{m}^{3}, 1\right)$ and $\chi^{2}(0.1 \mu \mathrm{m}$, $\left.1 \mu \mathrm{m}^{3}, 84,640 \mu \mathrm{m}^{3}, 1\right)$ value is 0.999 . This strong correlation could be due to the use of the same images taken by confocal microscopy and the fact that both analyses assay the uniformity of the distribution. However, the correlation coefficient between RDI $(0.1 \mu \mathrm{m}$, $\left.1 \mu \mathrm{m}^{3}, 84,640 \mu \mathrm{m}^{3}, 1\right)$ and absorbance is 0.735 . This poor correlation appears to be due to the RDI value of the $0.4 \mathrm{mg} / \mathrm{ml}$ sample. Without this sample, the correlation coefficient increases from 0.735 to 0.927 . In Section 3, the relationships between the dispersion levels determined by the above three analyses and various physical properties of the nanocomposites are obtained and compared to find which analysis best correlates with the properties.

\section{Basic PMMA/SWNT Nanocomposite Properties}

Thermal Stability Derivative weight loss rates of the six samples with respect to temperature in nitrogen are plotted in Figure 7. The peak weight loss rate was observed at $362{ }^{\circ} \mathrm{C}$ for pristine PMMA (plot not shown), $364{ }^{\circ} \mathrm{C}$ for the sample with the SWNT concentration in DMF at $1.2 \mathrm{mg} / \mathrm{ml}$, and at around $370{ }^{\circ} \mathrm{C}$ for all other samples. All the curves shown in this figure are close to each other. Thus, morphology difference in PMMA/SWNT nanocomposites does not appear to make an appreciable difference in the thermal stability of the nanocomposites.

Viscoelastic Properties The storage modulus $G^{\prime}$ provides a measure of nanocomposite "stiffness" and its frequency dependence characterizes whether the sample is in a liquid-like or a solid-like state. Comparison of the relationship of storage modulus as a function of frequency among the six nanocomposite samples is shown in Figure 8 at $200{ }^{\circ} \mathrm{C}$. $\mathrm{G}^{\prime}$ of the sample prepared at $1.2 \mathrm{mg} / \mathrm{ml}$ in DMF is not significantly different from that of PMMA and it shows the typical rheological response of a Newtonian liquid behavior with $\mathrm{G}^{\prime} \sim \omega^{2}$ (where $\omega$ is the oscillatory frequency) at low frequencies. However, $G^{\prime}$ increases significantly with a decrease in SWNT concentration in DMF and the liquid-like low frequency liquid-like scaling of $\mathrm{G}^{\prime}$ disappears. $\mathrm{G}^{\prime}$ is about the same for the three samples based on $0.05 \mathrm{mg} / \mathrm{ml}, 0.1 \mathrm{mg} / \mathrm{ml}$, and $0.2 \mathrm{mg} / \mathrm{ml}$ in DMF 
and $\mathrm{G}^{\prime}$ becomes nearly constant at low frequencies. This indicates a transition from a Newtonian liquid to an ideal Hookean solid, which accompanies the formation of a mechanically stable network structure [39] ('jammed network' or 'dispersion gel') [40]. The formation of such a structure has significant effects on flammability properties [41] as shown later in this paper.

Electrical Conductivity The complex conductivity $\sigma^{*}$ of our specimens can be expressed by Equation (6):

$$
\sigma^{*}=\sigma_{0}+j \omega \varepsilon_{0} \varepsilon_{r}^{*}
$$

where $\sigma_{0}$ is the direct current conductivity (DC), independent of $A C$ frequency $f, \omega=2 \pi f$, $\varepsilon_{r}^{*}$ is the complex dielectric permittivity of the composite material, $\varepsilon_{r}^{*}=\varepsilon_{0}\left(\varepsilon_{r}^{\prime}-j \varepsilon_{r}^{\prime \prime}\right)$, and $\varepsilon_{0}$ is the dielectric permittivity of free space. At low frequencies the complex admittance term, $\omega \varepsilon_{0} \varepsilon_{r}^{*}$, is small and the total conductivity becomes real $(\theta \approx 0$; $\left|\sigma^{*}\right|=\sigma_{0}$, ), independent of frequency, essentially equivalent to DC conductivity. Thus in the low frequency limit $\left|Z^{*}\right|_{(\mathrm{f} \rightarrow 0)}=Z_{0}$ and $\sigma_{0}=\frac{1}{Z_{0}} \frac{t}{a}$.

Figure 9 shows a log-log plot of complex conductivity of the six nanocomposite samples as a function of the frequency. The plateau seen in each plot extending up to a crossover frequency, $f_{c}$, corresponds to the DC conductivity $\sigma_{0}$ where $2 \pi f_{C} \varepsilon_{0}\left|\varepsilon_{r}^{*}\right|=\sigma_{0}$. It is seen that the samples prepared with $1.2 \mathrm{mg} / \mathrm{ml}$ in DMF exhibit a purely dielectric character. The linear frequency-dependent increase in complex conductivity on the log$\log$ plot corresponds to a dielectric constant of about 4.1. Similarly, samples with 0.8 $\mathrm{mg} / \mathrm{ml}$ show a dielectric behavior at frequencies above $f_{c} \approx 65 \mathrm{~Hz}$. However, with increasing dispersion of SWNT the nanocomposites became increasingly conducting while $f_{c}$ shifts to higher frequencies. The conductivity $\sigma_{0}$ increases from $10^{-7} \mathrm{~S} / \mathrm{m}$ and reaches a peak value of about $2.8 \times 10^{-3} \mathrm{~S} / \mathrm{m}$ at SWNT/DMF of $0.2 \mathrm{mg} / \mathrm{ml}$, while $f_{c}$ increases from $65 \mathrm{~Hz}$ to about $1.2 \mathrm{MHz}$. The conductivity results are summarized in Table 2, which shows significant effect of the dispersion level of SWNT on $\sigma_{0}$.

Flammability Property Mass loss rate curves in a nitrogen atmosphere at an external flux of $50 \mathrm{~kW} / \mathrm{m}^{2}$ are shown in Fig. 11. All samples were tested with $4 \mathrm{~mm}$ 
thick samples except for a $8 \mathrm{~mm}$ thick sample prepared at $0.2 \mathrm{mg} / \mathrm{ml}$ concentration in DMF. This particular sample was tested in our previous study [36]. It is expected that the effect of the difference between $8 \mathrm{~mm}$ thickness and $4 \mathrm{~mm}$ thickness on mass loss rate curve is not significant, except to give roughly twice longer test time for the $8 \mathrm{~mm}$ thick sample than that for the $4 \mathrm{~mm}$ thick sample. (This is the reason why the upper time scale, which applies only to the sample prepared with $0.2 \mathrm{mg} / \mathrm{ml}$ concentration in DMF $(8 \mathrm{~mm})$, is twice a long as the lower time scale for all other samples.) Lower mass loss rate implies lower heat release rate during burning and thus lower flammability. Figure 10 shows the significant effects of the morphology difference on mass loss rate. The mass loss rate of sample prepared with $0.2 \mathrm{mg} / \mathrm{ml}$ concentration in DMF is roughly $1 / 3$ of that of pristine PMMA compared to a small reduction of only $10 \%-20 \%$ with samples prepared at $0.8 \mathrm{mg} / \mathrm{ml}$ and $1.2 \mathrm{mg} / \mathrm{ml}$ concentrations in DMF despite there being the same amount of SWNT in all samples. The pictures of the residues collected at the end of the tests show a relatively uniform, smooth surface for the sample prepared at $0.2 \mathrm{mg} / \mathrm{ml}$ concentration in DMF compared to many large islands for the sample prepared at 0.8 $\mathrm{mg} / \mathrm{ml}$ concentration in DMF (figure inserts). During the test for the latter sample, vigorous bubbling was observed between the islands but no bubbling was observed except in the very early stages of the test (within first $30 \mathrm{~s}$ ) for the sample prepared at 0.2 $\mathrm{mg} / \mathrm{ml}$ concentration in DMF. This observation and the relationship between the formation of a uniform residue versus the formation of islands and the mass loss rate curves are consistent with our previous observation [36,41].

\section{Relationship Between Quantitative Dispersion Level and Physical Properties}

As shown above, there are no significant effects of the dispersion level of SWNT in the PMMA/SWNT(0.5\%) nanocomposites on thermal stability. Relationships between the dispersion level and physical properties, such as storage modulus, electrical conductivity, and flammability properties of the nanocomposites are obtained. Since the

quantified dispersion level by RDI is very similar to that by $\chi^{2}$ analysis, as shown in Figure 6, only the former analysis as well as absorbance is used as measures of dispersion level. 
The relationships between storage modulus at $0.05 \mathrm{rad} / \mathrm{s}$ in Figure 8 and dispersion level quantified by RDI $\left(0.1 \mu \mathrm{m}, 1 \mu \mathrm{m}^{3}, 84,640 \mu \mathrm{m}^{3}, 1\right)$ and absorbance at wavelength $275 \mathrm{~nm}$ in Figure 5 are plotted in Figure 11. The second order polynomials fit best as compared to a power fit or an exponential fit. Both fits show a rapid increase in the storage modulus at low dispersion levels followed by slow increase in storage modulus at high dispersion levels. The storage modulus evidently correlates with the dispersion level determined by absorbance better than with that measured by RDI ( 0.1 $\left.\mu \mathrm{m}, 1 \mu \mathrm{m}^{3}, 84,640 \mu \mathrm{m}^{3}, 1\right)$. The correlation coefficient of the former is 0.97 compared to 0.84 for the latter. The figure also indicates that storage modulus can vary about four orders of magnitude with dispersion level for a fixed SWNT concentration $(0.5 \%)$ in the nanocomposites.

The corresponding relationship between dispersion level and electrical conductivity is shown in Figure 12. Both a power fit and an exponential fit correlate well with either RDI or absorbance (A polynomial fit was also used but a fit with the highest correlation coefficient was selected in this study.). The correlation coefficient of the power fit with RDI is 0.99 and with absorbance is 0.96 . The electrical conductivity varies by roughly $10^{8}$ orders with dispersion level for a fixed SWNT concentration, an effect even more drastic than for storage modulus. The electric conductivity increases rapidly with an increase in the dispersion level, but the increase in electrical conductivity with an increase in dispersion level becomes lower when the dispersion level is relatively high.

Next, the effect of dispersion level on normalized peak mass loss rate of the nanocomposites is shown in Figure 13, given recent interest in SWNT as a fire retardant additive [36]. The abscissa of the figure is the ratio of the peak mass loss rate of PMMA/SWNT (0.5 \%) nanocomposites divided by the peak mass loss rate of PMMA measured at an external radiant flux of $50 \mathrm{~kW} / \mathrm{m}^{2}$ in a nitrogen atmosphere. The smaller the ratio the less flammable is the sample. The figure shows about an approximately $70 \%$ reduction in flammability is achieved with the best dispersed sample tested in this study, so that we again find a large effect of dispersion level on an important property of these nanocomposites. Contrary to the above trend observed for storage modulus and electric conductivity, it appears that the peak mass loss rate is monotonically reduced even at the high end of dispersion level (no plateau). The second order polynomial fit correlates best 
as compared to a power fit and an exponential fit. The correlation coefficient of the fit with absorbance is 0.99 compared to 0.96 with RDI.

\section{Discussion}

Our measurements of SWNT nanocomposite properties over a wide range of dispersion level indicate a profound variation in the properties of the nanocomposites and the evident need for dispersion metrics to allow some control of these properties and some understanding of why these property changes come about. The majority of studies show few TEM or SEM images comprising only a few nanocomposite samples without any analyses and assume that the dispersion levels of the all samples are the same. However, without any quantitative analyses of spatial dispersion in all of the samples, the dispersion level of each sample might differ. At higher concentrations of nanoparticles, distances between nanoparticles become less and nanoparticles tend to agglomerate or bundle with each other. Thus, it tends to get more difficult to achieve good dispersion of nanoparticles in nanocomposites at high concentrations of nanoparticles. This might be one of reasons why the reported concentrations of nanoparticles needed to attain percolation in electrical conductivity and in storage modulus differ significantly among published papers.

We would like to understand better the sources of uncertainty in estimate of the RDI. There are several possible reasons. (1) The spatial resolution of the images taken by confocal microscopy might not be fine enough to detect smaller bundles of SWNTs or single SWNTs, although their actual amounts in the samples were not known. The analysis used in this study might be more appropriate for larger tubes. (2) Although the observed volume is relatively large compared to those seen by TEM and SEM, only one location of each sample was analyzed. The three-dimensional image of the sample prepared at $0.4 \mathrm{mg} / \mathrm{ml}$ concentration in DMF shown in Figure 1(b) appears to show a more uniform distribution than the other images. There might be larger scale nonuniformity in some of samples. The same analysis used in this study might need to be applied to a number of statistically selected locations in the sample to get an overall dispersion level. (3) In the analysis, a threshold value (taken from the background measurement of the confocal image of pristine PMMA) was used to determine whether 
there was a tube bundle (designated as " 1 ") or not (designated as " 0 ") in each cell of about $90 \mathrm{~nm}$ x $90 \mathrm{~nm}$ x $100 \mathrm{~nm}$ size. However, we did not determine whether there was more than one tube bundle or not. The analysis clearly requires further refinement to include the relationship between intensity and the number of tube bundles.

The analysis based on absorbance measurement is relatively easy and does not take too much time. However, this approach may not be used for samples with higher concentration of tubes because the absorbance becomes too high to allow application of the Beer-Lambert law described by Equation 4. For a comparison of the dispersion between two different resins and/or different nanoparticles, this approach requires multiple calibrations and consequently it could become more complicated. It would appear to be most suited for comparison of the dispersion of the same type of nanoparticles with different sample preparation conditions, for example different mixing times, but keeping the same composition. Although the analysis using confocal microscopy might need further improvements to remove the above uncertainties, it can apply to higher concentration samples and it might also be possible to compare two different sample types based on different resins and/or different types of particles. Although a uniform distribution of tubes in nanocomposites is one of the requirements for better physical properties, electrical conductivity of nanocomposites can be significantly increased with specific alignment of tubes [42] or the formation of interconnected agglomerates [43]. Therefore, three-dimensional reconstructed images by X-ray transmission could be used to obtain detailed morphology including distribution, orientation, size, if the spatial resolution of this method were to be improved [44].

\section{Conclusions}

Relation between our relative dispersion metric and the properties of PMMA/SWNT nanocomposites was obtained at a fixed SWNT concentration of $0.5 \%$. When the sample preparation method led to large range of dispersions in the samples, the dispersion metric of SWNTs was determined by two different methods, one was an absorbance measurement by UV-Vis spectroscopy and the other was a statistical analysis of 100 images taken by confocal microscopy. The observation domain of the former was about $3 \mathrm{~mm} \times 10 \mathrm{~mm} \times 200 \mu \mathrm{m}$ thickness and that of the latter was about $92 \mu \mathrm{m} \times 92 \mu \mathrm{m}$ 
x $10 \mu \mathrm{m}$ thickness. Quantitative spatial dispersion levels were obtained through image analysis to obtain a 'relative dispersion index' representing the uniformity of the dispersion of SWNTs in the samples and through the absorbance. The storage modulus, electrical conductivity, and flammability property (normalized peak mass loss rate) of the PMMA/SWNT(0.5\%) nanocomposites are well correlated with respect to the quantified dispersion levels determined by the two different analyses. The relation between the quantified dispersion levels and physical properties shows about four orders of magnitude variation in the storage modulus, almost eight orders of magnitude variation in electrical conductivity, and about $70 \%$ reduction in peak mass loss rate at the highest dispersion level used in this study. With the profound effects of dispersion of SWNTs, objective dispersion metrics in an appropriate scale must be measured to understand how the properties of nanocomposites depend on the concentration, shape and size of the nanotubes and the reproducibility of the properties in the preparation of samples under nominally fixed preparation conditions.

\section{Acknowledgement}

We thank Mr. John R. Shields and Mr. Jason Marple at NIST for helping with the flammability test, taking TGA data, and preparing sample discs. We also thank Dr. Shinnosuke Nishiki for his help to make the three dimensional images shown in Figure 1 and Carbon Nanotechnologies Incorporated and Foster Miller Company for providing SWNTs. T.K. acknowledges funding from NIST with a grant number of 5D1022.

\section{Figure Captions}

Figure 1. Three-dimensional images constructed from confocal microscopy images of the PMMA / SWNT(0.5 \%) nanocomposite samples prepared with various SWNT concentrations in DMF: (a) $0.2 \mathrm{mg} / \mathrm{ml}$, (b) $0.4 \mathrm{mg} / \mathrm{ml}$, (c) $0.8 \mathrm{mg} / \mathrm{ml}$, and (d) $1.2 \mathrm{mg} / \mathrm{ml}$. The size of the observation domain is $23 \mu \mathrm{m} \times 23 \mu \mathrm{m} \times 9.2 \mu \mathrm{m}$ depth.

Figure 2. Relative dispersion indecies (RDI) of SWNT in PMMA / SWNT(0.5 \%) nanocomposites prepared with various concentrations of SWNT in DMF $(\mathrm{mg} / \mathrm{ml})$ vs the domain size. 
Figure 3. $\chi^{2}$ values describing the dispersion level of SWNT in PMMA/SWNT(0.5\%) nanocomposites prepared with various concentrations of SWNT in DMF (unit of $\mathrm{mg} / \mathrm{ml}$ ) vs. the domain size.

Figure 4. Scaled absorption spectra of the six PMMA/SWNT(0.5 \%) samples prepared with different concentrations of SWNT in DMF.

Figure 5. (a). The average transmittance and corresponding absorbance for three illustrated lateral distributions of an absorbing material. The distribution affects the apparent concentration calculated using the assumption of homogeneity implicit in Eq.(4). (b) Photograph of the PMMA / SWNT(0.5 \%) films used for the absorbance measurement. The differences in opacity are due primarily to the relative level of dispersion in each film.

Figure 6. Relationship among relative dispersion index $\left(0.1 \mu \mathrm{m}, 1 \mu \mathrm{m}^{3}, 84,640 \mu \mathrm{m}^{3}, 1\right)$, $\chi^{2}\left(0.1 \mu \mathrm{m}, 1 \mu \mathrm{m}^{3}, 84,640 \mu \mathrm{m}^{3}, 1\right)$ with open squares, and absorbance at $275 \mathrm{~nm}$ with solid circles. $\mathrm{R}$ is correlation coefficient.

Figure 7. DTG, dynamic thermogravimetric, curves of the six PMMA/SWNT( $0.5 \%)$ nanocomposites prepared by different SWNT concentrations in DMF. TGA was conducted in nitrogen at heating rate of $5{ }^{\circ} \mathrm{C} / \mathrm{min}$.

Figure 8. Storage modulus vs frequency for the PMMA / SWNT(0.5\%) nanocomposites prepared with various concentration of SWNT in DMF ( $\mathrm{mg} / \mathrm{ml})$.

Figure 9. Complex electrical conductivity vs frequency for the PMMA / SWNT(0.5\%) nanocomposites prepared with various concentrations of SWNT in DMF $(\mathrm{mg} / \mathrm{ml})$.

Figure 10. Mass loss rate curves of PMMA / SWNT(0.5 \%) nanocomposites prepared with various concentrations of SWNT in DMF $(\mathrm{mg} / \mathrm{ml})$. All samples were $4 \mathrm{~mm}$ thick except $8 \mathrm{~mm}$ thick for $0.2 \mathrm{mg} / \mathrm{ml}$. Tests were conducted at $50 \mathrm{~kW} / \mathrm{m}^{2}$ in a nitrogen atmosphere.

Figure 11. The relationships between storage modulus of PMMA / SWNT $(0.5 \%)$ at 0.5 $\mathrm{rad} / \mathrm{s}$ and quantitative dispersion levels of SWNT described with relative dispersion index $\left(0.1 \mu \mathrm{m}, 1 \mu \mathrm{m}^{3}, 84,640 \mu \mathrm{m}^{3}, 1\right)$ (solid circles) and with absorbance at $275 \mathrm{~nm}$ (open squares). Second order polynomial fits and correlation coefficient, R, with RDI is 0.84 and that with absorbance is 0.97 . 
Figure 12. The relationships between electric conductivity of PMMA/SWNT(0.5\%) and electrical conductivity and quantitative dispersion levels of SWNT described with relative dispersion index $\left(0.1 \mu \mathrm{m}, 1 \mu \mathrm{m}^{3}, 84,640 \mu \mathrm{m}^{3}, 1\right)$ (solid circles) and with absorbance at $275 \mathrm{~nm}$ (open squares). Power fits and correlation coefficient, R, with RDI is 0.99 and that with absorbance is 0.96 .

Figure 13. The relationships between the normalized peak mass loss rate of PMMA/SWNT( $0.5 \%$ ) by the peak mass loss rate of PMMA and quantitative dispersion levels of SWNT described with relative dispersion index $\left(0.1 \mu \mathrm{m}, 1 \mu \mathrm{m}^{3}, 84,640 \mu \mathrm{m}^{3}, 1\right)$ (solid circles) and with absorbance at $275 \mathrm{~nm}$ (open squares). Second order polynomial fits and correlation coefficient, R, with RDI is 0.96 and that with absorbance is 0.99 .

Table 1. SWNT concentration in DMF versus scaled absorbance (at $275 \mathbf{~ n m}$ ), Relative dispersion index $\left(0.1 \mu \mathrm{m}, 1 \mu^{3}, 84,640 \mathrm{~m}^{3}, 1\right)$ and $\chi^{2}\left(0.1 \mu \mathrm{m}, 1 \mathrm{~m}^{3}\right.$, $\left.84,640 \mu^{3}, 1\right)$

\begin{tabular}{llll} 
SWNT concentration in DMF & Absorbance & RDI & $\chi^{2}$ \\
\hline $0.05 \mathrm{mg} / \mathrm{ml}$ & & & \\
0.1 & 2.75 & $61(\%)$ & $6.3 \times 10^{5}$ \\
0.2 & 2.60 & 64 & $1.4 \times 10^{5}$ \\
0.4 & 3.06 & 77 & $1.1 \times 10^{5}$ \\
0.8 & 1.80 & 81 & $1.0 \times 10^{5}$ \\
1.2 & 1.20 & 53 & $8.0 \times 10^{5}$ \\
& 0.56 & 28 & $2.5 \times 10^{6}$
\end{tabular}


Table 2. Effects of SWNT concentration in DMF on electrical conductivity of PMMA/SWNT(0.5 \%)

\begin{tabular}{cl}
$\begin{array}{l}\mathrm{SWNT} / \mathrm{DMF} \\
(\mathrm{mg} / \mathrm{ml})\end{array}$ & $\begin{array}{l}\sigma_{0} \\
(\mathrm{~S} / \mathrm{m})\end{array}$ \\
\hline 0.05 & $2.8 \times 10^{-4}$ \\
0.1 & $5.2 \times 10^{-4}$ \\
0.2 & $2.8 \times 10^{-3}$ \\
0.4 & $8.6 \times 10^{-5}$ \\
0.8 & $2.0 \times 10^{-7}$ \\
1.2 & $3.2 \times 10^{-10}$
\end{tabular}


(a)

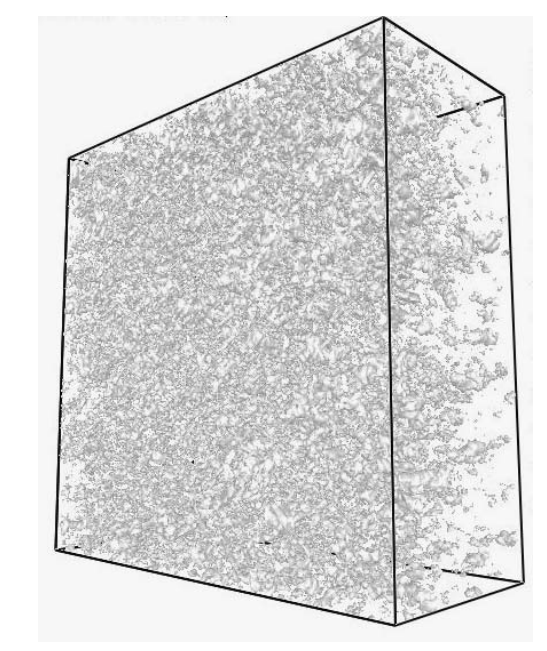

(c)

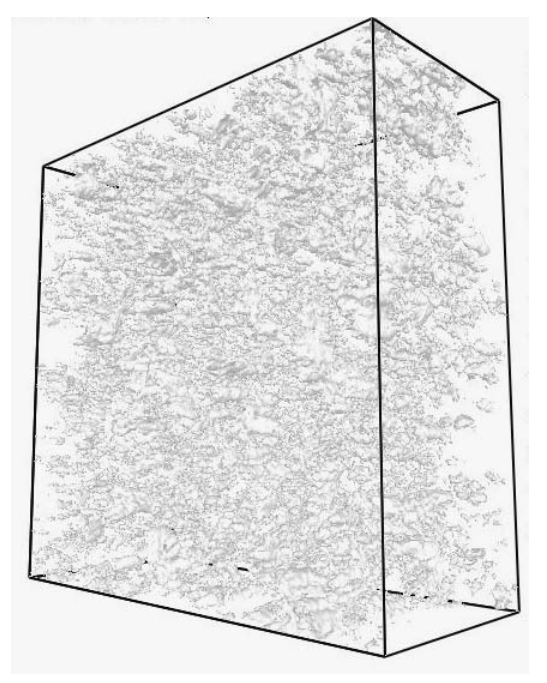

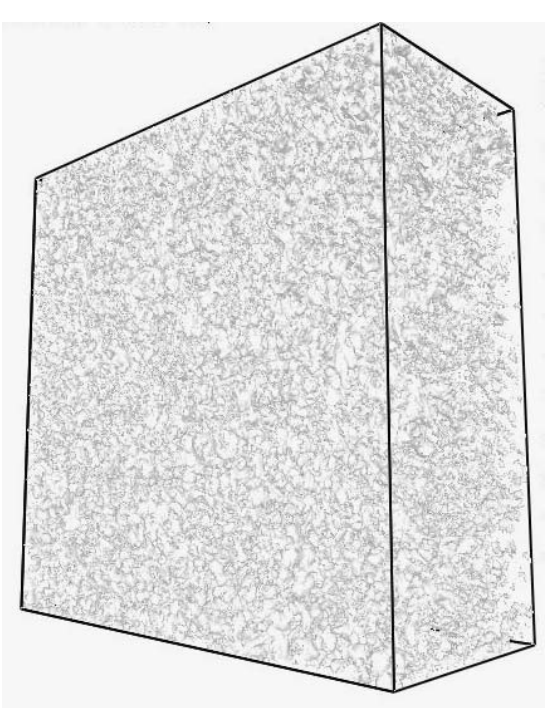

(b)

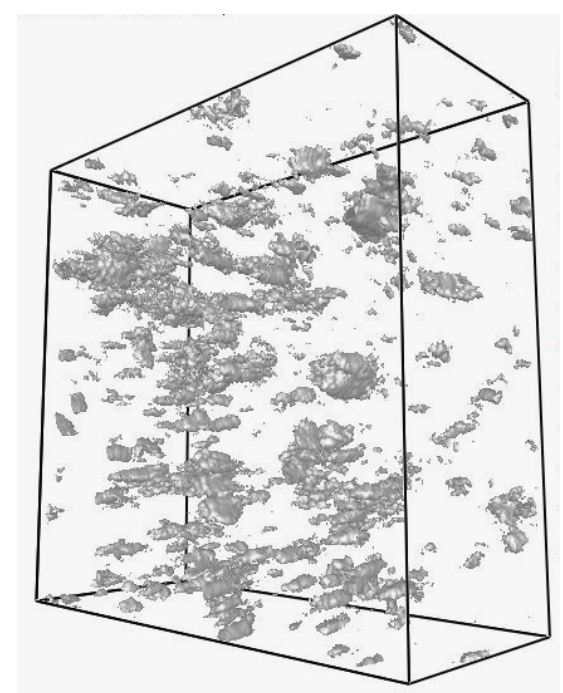

(d)

Figure1 


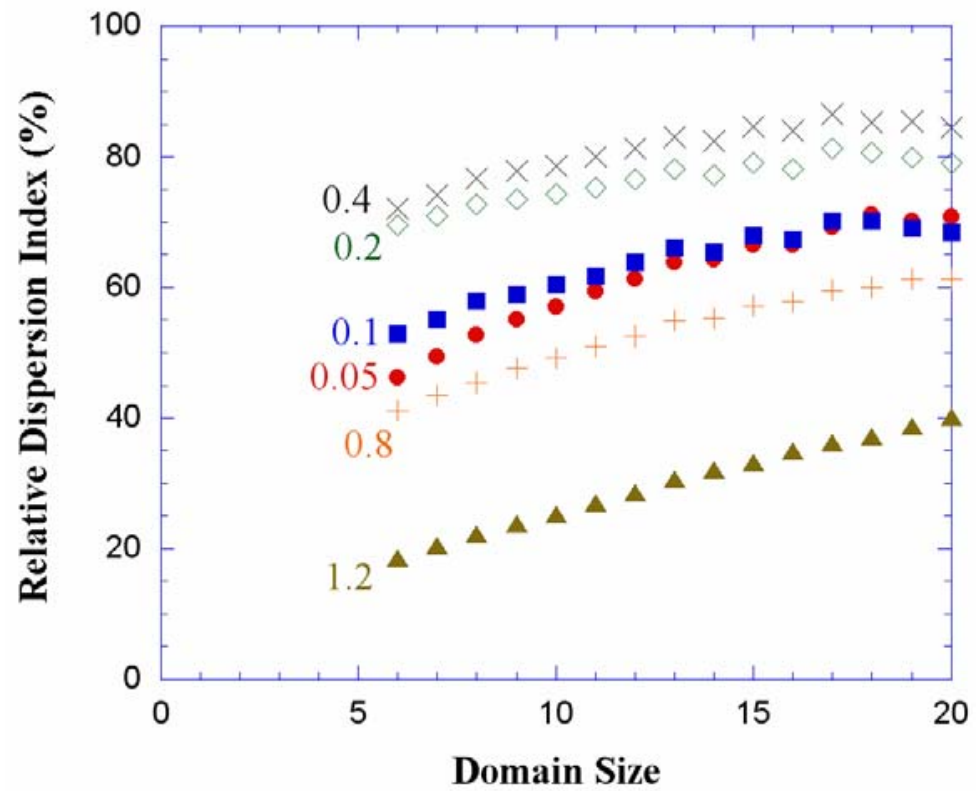

Figure 2

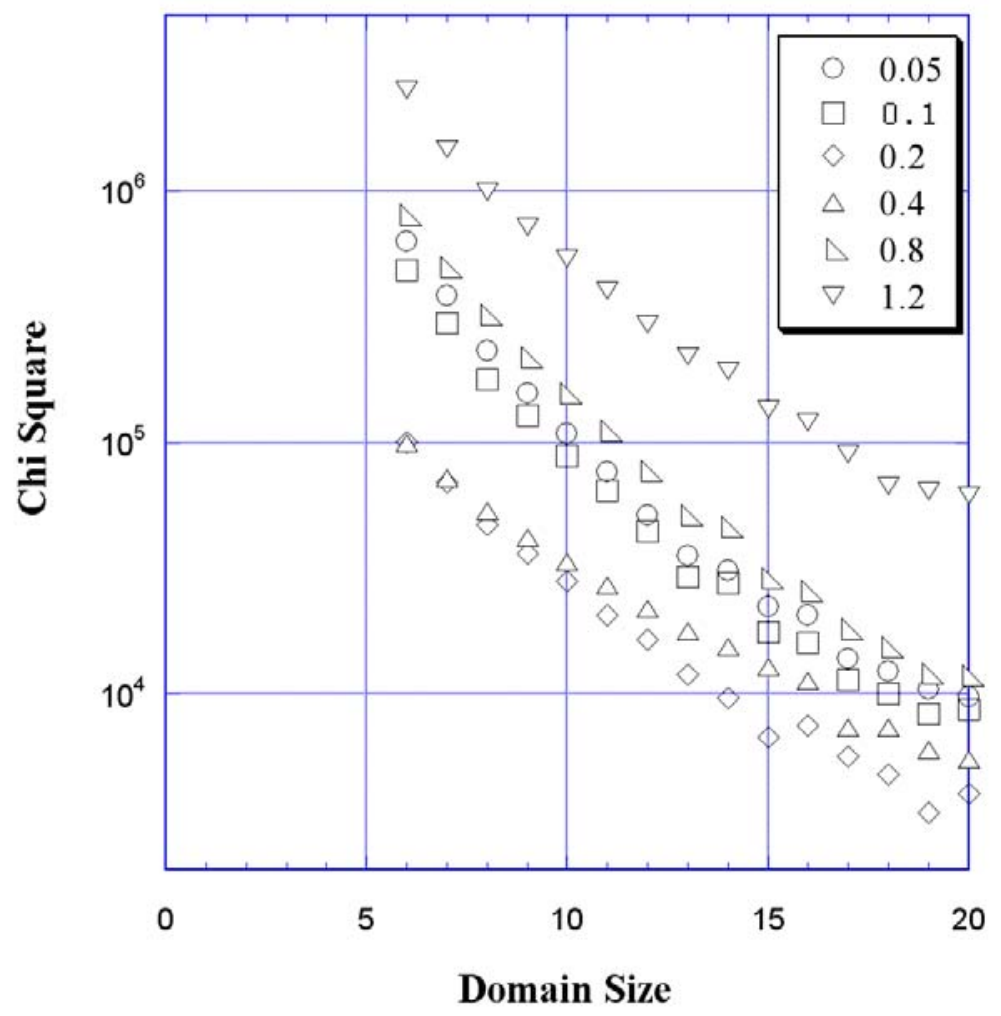

Figure 3 


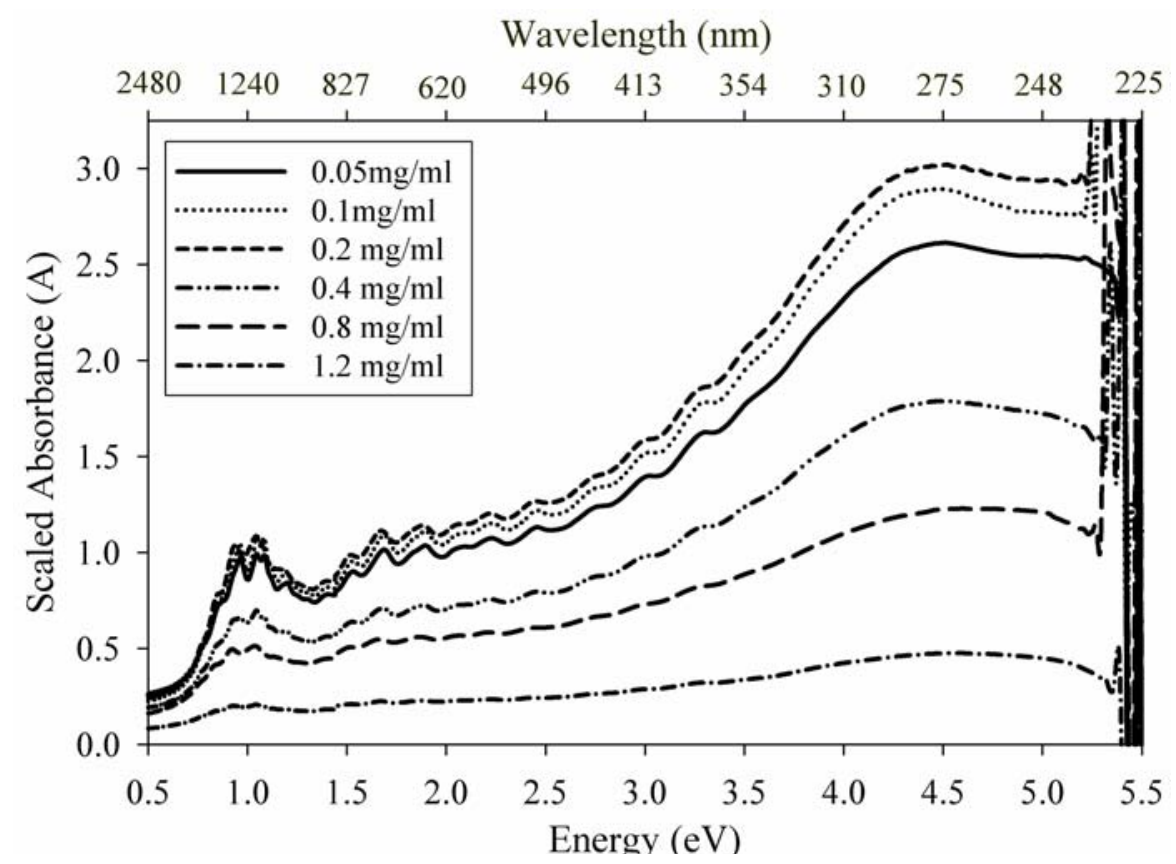

Figure 4

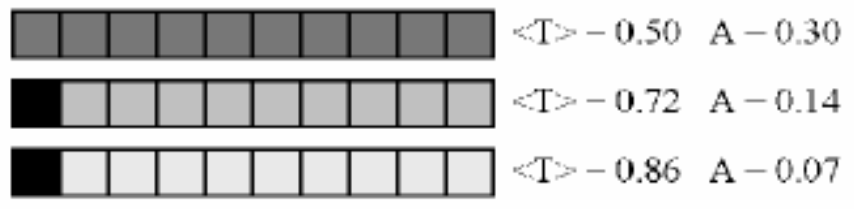

(a)

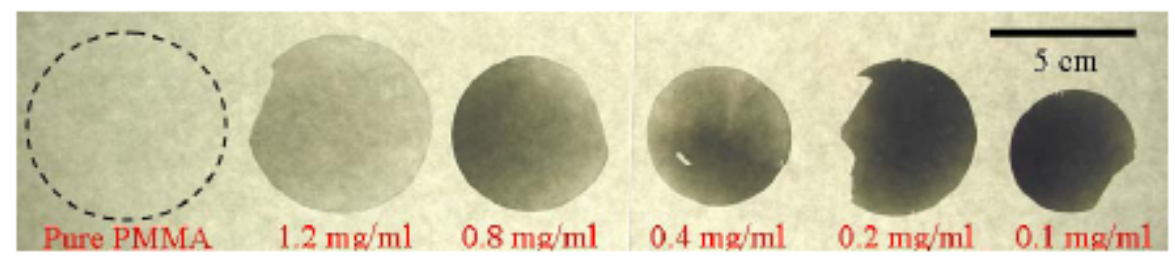

(b)

Figure 5 


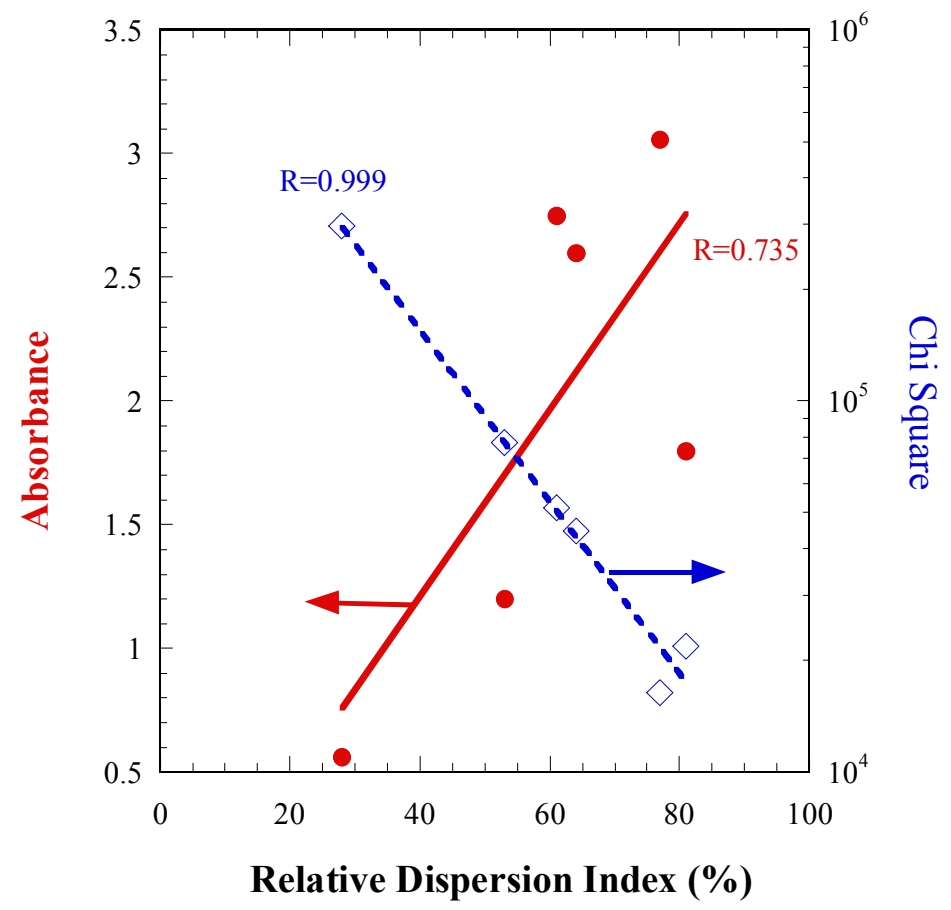

Fig. 6

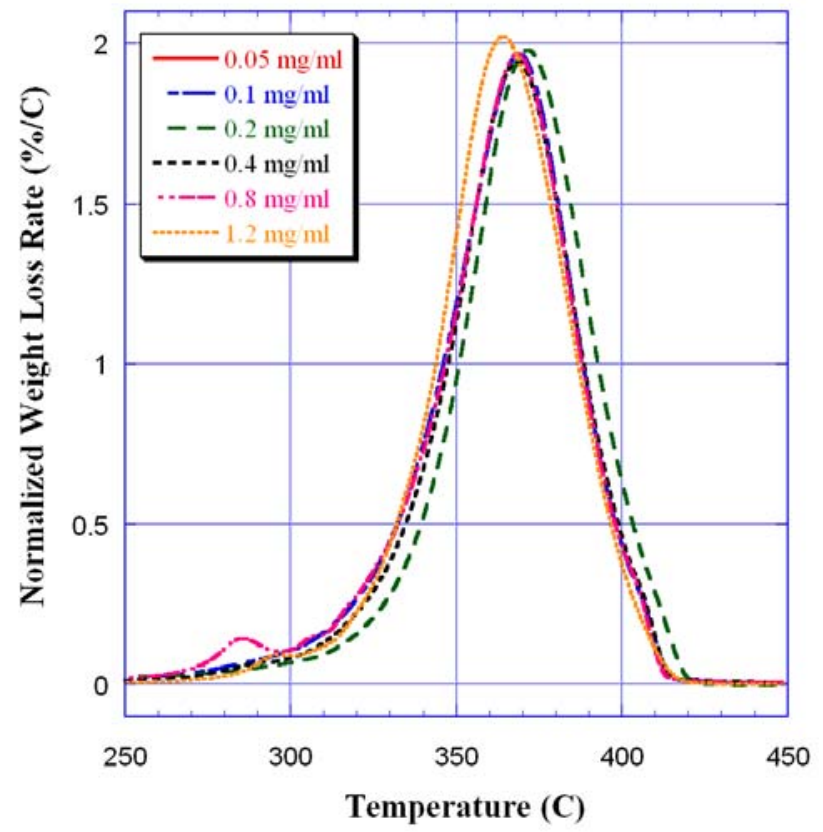

Figure 7 


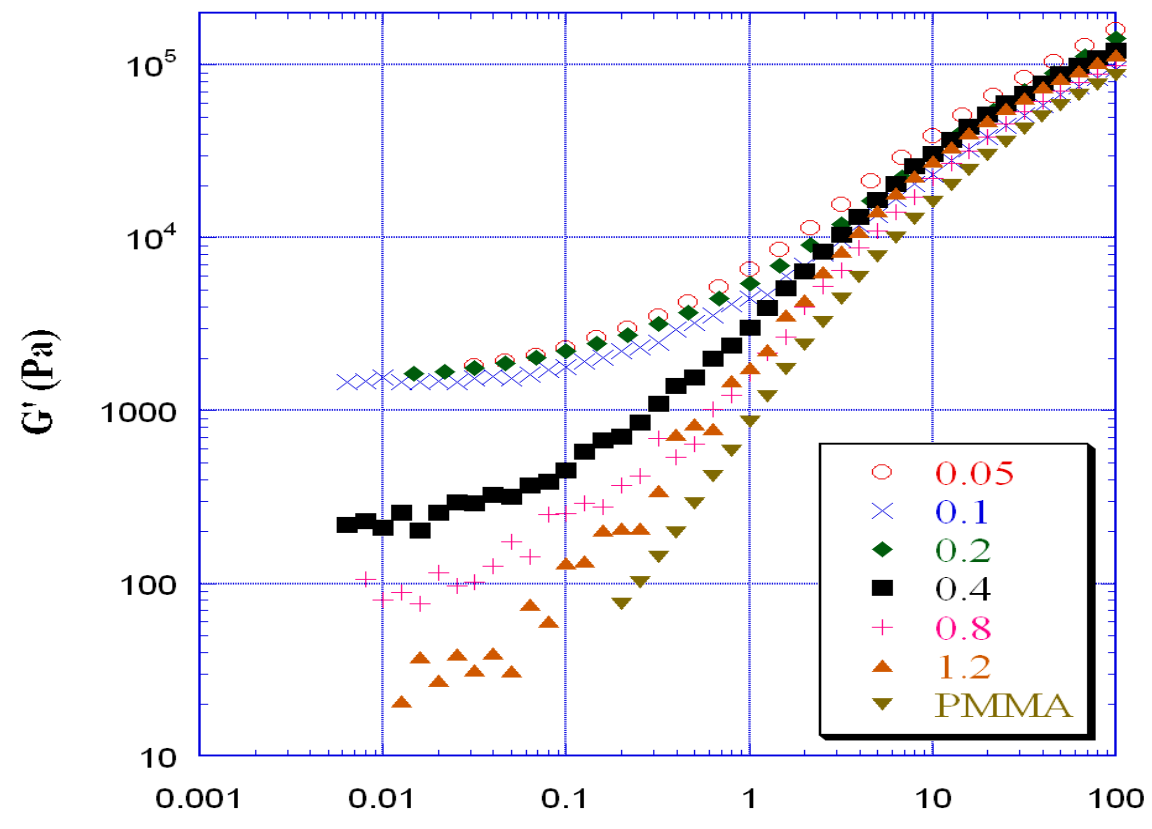

Frequency (rad/s)

Figure 8

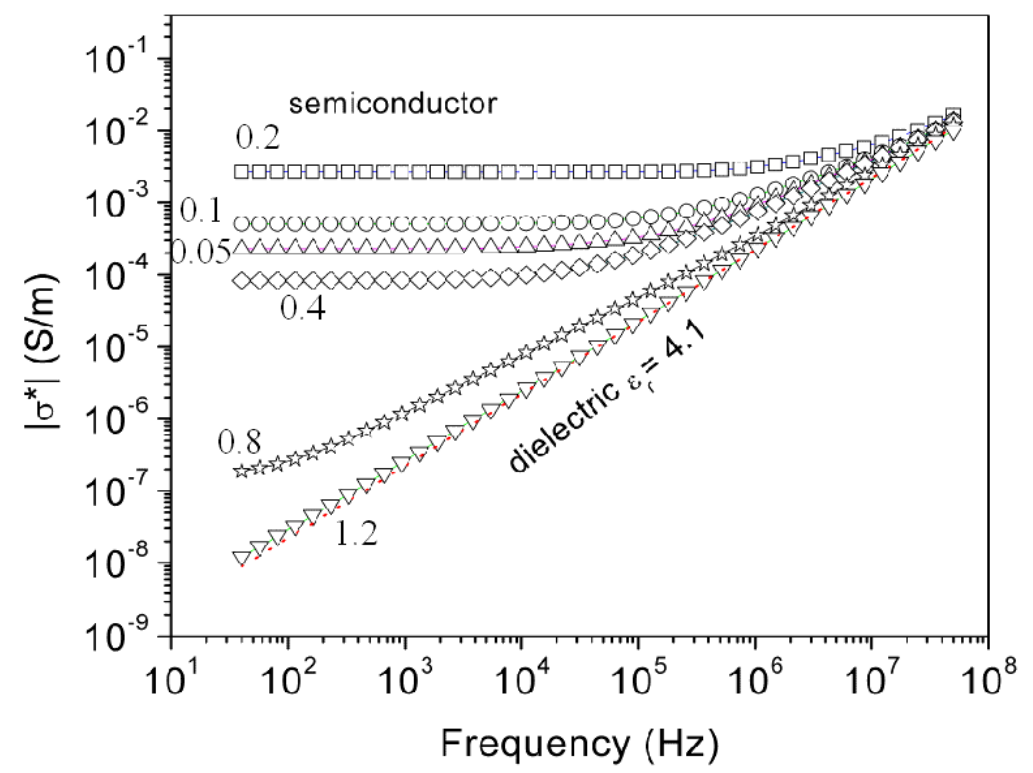

Figure 9 


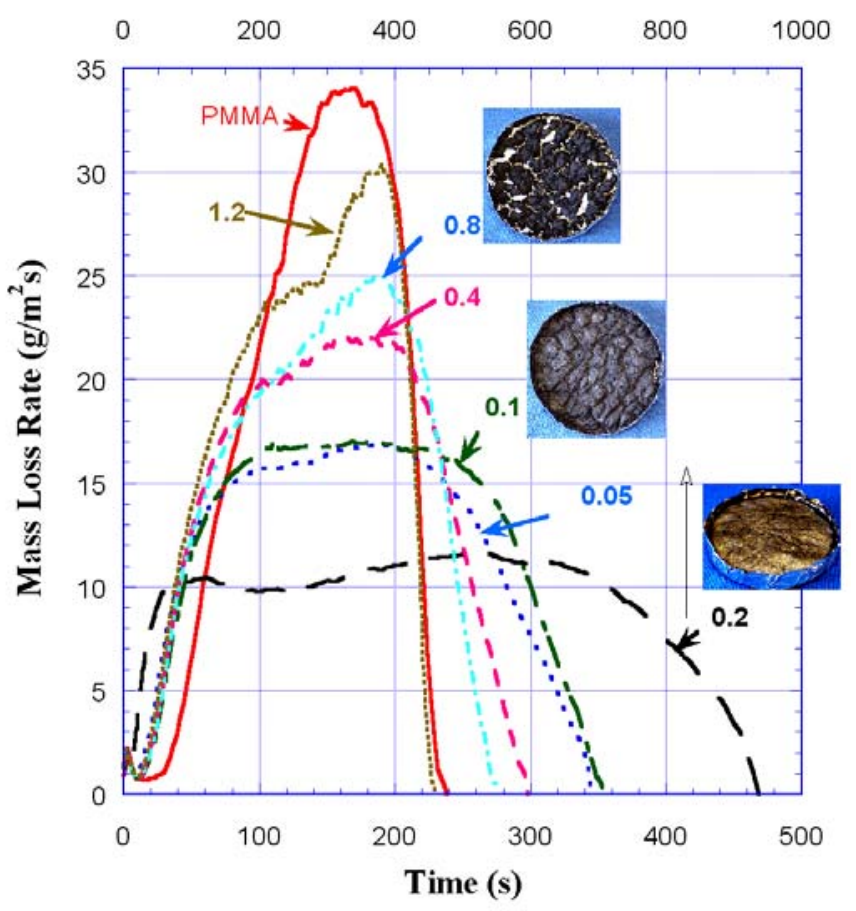

Figure 10

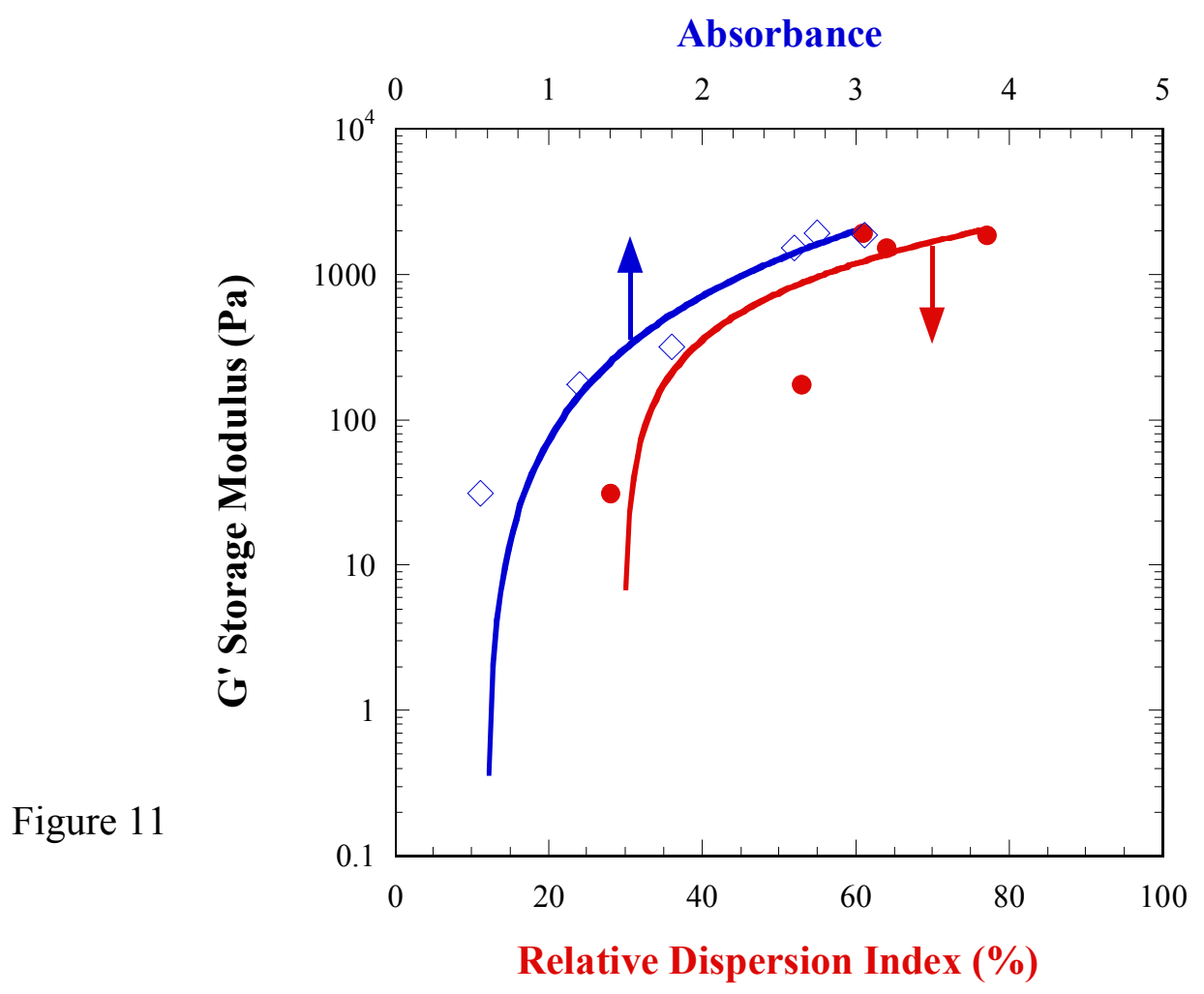



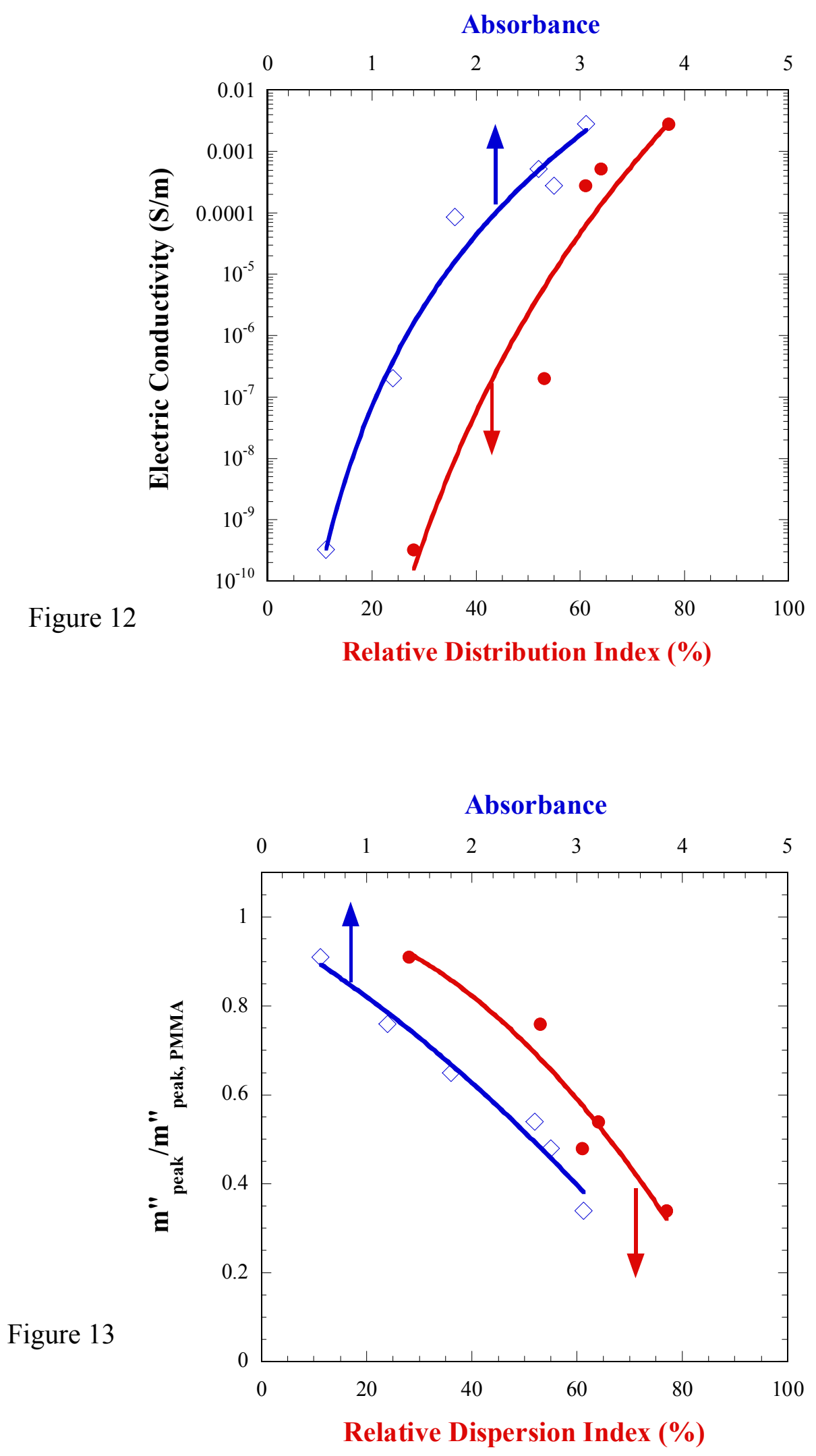


\section{References}

${ }^{1}$ Iijima S. Nature 1991; 354: 603-605.

${ }^{2}$ Schadler LS, Giannaris SC, Ajayan PM. Appl. Phys. Lett. 1998; 73: 3842-3844.

${ }^{3}$ Stephan C, Nguyen TP, Lahr B. Blau W, Lefrant S, Chauvet O. J. Mater. Res. 2002; 17: 396-400.

${ }^{4}$ Dalton AB, Collins S, Munoz E, Razal JM, Ebron VH, Ferraris JP, Coleman JN, Kim BG, Baughman RH. Nature, 2003; 423: 703.

${ }^{5}$ Barrau S, Demont P, Peigney A, Laurent C, Lacabanne C. Macromolecules, 2003; 36: 5187-5194.

${ }^{6}$ Thostenson ET, Chou,T-W. J. Phys. D : Appl. Phys. 2003; 36: 573-582.

${ }^{7}$ Coleman JN, Khan U, Blau WJ, Gun'ko YK. Carbon, 2006 ; 44 : 1624-1652.

${ }^{8}$ Moniruzzaman M, Winey KI. Macromolecules, 2006; 39: 5194-5205.

${ }^{9}$ Mitchell CA, Bahr JL, Arepalli S, Tour JM, Krishnamoorti R. Macromolecules, 2002; 35: $8825-8830$.

${ }^{10}$ Ramanathan T, Liu H, Brinson LC. J. Polym. Sci. Part B, Polym. Phys. 2005; 43: 22692279.

${ }^{11}$ Vaisman L, Marom G, Wagner HD. Adv. Funct. Mater. 2006; 16: 357-363.

${ }^{12}$ Schaefer DW, Zhao J, Brown JM, Anderson DP, Tomlin DW. Chem.Phys. Lett. 2003; 375: $369-375$.

${ }^{13}$ Du F, Scogna RC, Zhou W, Brand S, Fischer JF, Winey KI. Macromolecules, 2004; 37: 9048-9055.

${ }^{14}$ Liao Y-H, Marietta-Tondin O, Liang Z, Zhang C, Wang B. Mater.Sci. Eng. A, 2004 ; 385: $175-181$.

${ }^{15}$ Song W, Windle AH. Macromolecules, 2005; 38: 6181-6188.

${ }^{16}$ Song YS, Youn JR. Carbon, 2005; 43: 1378-1385.

${ }^{17}$ Park C, Ounaies Z, Watson KA, Crooks RE, Smith Jr J, Lowther SE, Connell JW, Siochi EJ, Harrison JS, St. Clair TL. Chem. Phys. Lett., 2002; 364: 303-308.

${ }^{18}$ Park SJ, Cho MS, Lim ST, Choi HJ, Jhon MS. Macromol. Rapid Commun., 2003; 24: 1070-1073.

${ }^{19}$ Martin CA, Sandler JKW, Shaffer MSP, Schwarz MK, Bauhofer W, Schulte K, Windle AH. Composites Sci. Tech., 2004; 64: 2309-2316. 
${ }^{20}$ Huang YY, Ahir SV, Terentjev EM. Phys. Rev. B. 2006; 73: 125422.

${ }^{21}$ Sennett M, Welsh E, Wright JB, Li WZ, Wen JG, Ren ZF. Appl. Phys. A., 2003; 76: 111-113.

${ }^{22}$ Kashiwagi T, Grulke E, Hilding J, Groth K, Harris R, Butler K, Shields J, Kharchenko

S, Douglas J. Polymer, 2004; 45: 4227-4239.

${ }^{23}$ Krishnamoorti R. MRS Bulltin, 2007; 32: 341-347.

${ }^{24}$ Balazs AC, Emrick T, Russell TP. Science, 2006; 314: 1107-1110.

${ }^{25}$ Fagan JA, Landi BJ, Mandelbaum I, Simpson JR, Bajpai V, Bauer BJ, Milger K, Hight Walker AR, Raffaelle R, Hobbie EK. J. Phys. Chem. B, 2006; 110: 23801-23805.

${ }^{26}$ Bellayer S, Gilman JW, Eidelman N, Bourbigot S, Flambard X, Fox DM, De Long HC, Trulove PC. Adv. Funct. Mater. 2005; 15: 910-916.

${ }^{27}$ Ratinac KR, Gilbert RG, Ye L, Jones AL, Ringer SP. Polymer, 2006; 47: 6337-6361.

${ }^{28}$ Tan Y, Resasco DE. J. Phys. Chem. B 2005; 109: 14454-14460.

${ }^{29}$ Yalcin B, Cakmak M. Polymer, 2004; 45: 6623-6638.

${ }^{30}$ Konishi Y, Cakmak M. Polymer, 2006; 47: 5371-5391.

${ }^{31}$ Morishita M. Memories of the faculty of science series E, Biology, Kyushu University, Fukuoka, Japan, 1959; 2: 215.

${ }^{32}$ Nikolaev P, Bronikowski MJ, Bradley RK, Rohmund FR, Colbert DT, Smith KA, Smalley RE. Chem. Phys. Lett, 1999; 313: 91.

${ }^{33}$ Du F, Fischer JE, Winey KI. J. Polym. Sci.: Part B, Polym. Phy., 2003;41: 3333-3338.

${ }^{34}$ Fortin M-J, Dale M. Spatial Analysis: A guide for ecologist. 2005, Cambridge Univ. Press, Cambridge, U.K.

${ }^{35}$ Blom G, Holst L, Sandell D. Problems and snapshots from the world of probability, 1991, Springer-Verlag, New York.

${ }^{36}$ Kashiwagi T, Du F, Winey KI, Groth KM, Shields JR, Bellayer SP, Kim H, Douglas JF. Polymer, 2005; 46: 471-481.

${ }^{37}$ Kashiwagi T, Harris RH, Zhang X, Briber RM, Cipriano BH, Raghavan SR, Awad WH, Shields JR. Polymer, 2004; 45: 881-891.

${ }^{38}$ Austin PJ, Buch RR, Kashiwagi T. Fire Mater. 1998; 22: 221-237. 
${ }^{39}$ Kharchenko SB, Douglas JF, Obrzut J, Grulke EA, Milger KB. Nature Mater. 2004; 3 : 564-568.

${ }^{40}$ Bicerano J, Douglas JF, Brune DA. J.M.S. - Rev. Macromol. Chem. Phys. 1999; C39: 561-642.

${ }^{41}$ Kashiwagi T, Du F, Douglas JF, Winey KI, Harris RH Jr, Shields J. Nature Mater. 2005; 4: 928-933.

${ }^{42}$ Du F, Fischer JE, Winey KI. Phy. Rev. B, 2005; 121404(R).

${ }^{43}$ Martin CA, Sandler JKW, Shaffer MSP, Schwarz MK, Bauhofer W, Schulte K, Windle AH. Composit. Sci. Tech., 2004; 64: 2309-2316.

${ }^{44}$ Larson BC, Lengeler B. MRS Bulletin, 2004; 29: 152-156. 